\title{
Integration of physiological and molecular mechanisms of the developmental origins of adult disease: new concepts and insights
}

\author{
Michael E. Symonds \\ Centre for Reproduction and Early Life, Institute of Clinical Research, University of Nottingham, \\ Nottingham NG7 2UH, UK
}

\begin{abstract}
It is now well established that an imbalance or reduction in the maternal diet either through pregnancy and lactation or at defined time points therein can have long-term effects on cardiovascular and metabolic health in the resulting offspring; the exact outcome varying greatly with the period of development or growth targeted. The EARly Nutrition programming - longterm follow up of Efficacy and Safety Trials and integrated epidemiological, genetic, animal, consumer and economic research (EARNEST), or metabolic programming, project aims to determine the primary physiological and molecular mechanisms that cause long-term changes in both cardiovascular function and metabolic homeostasis. Thereafter, it also aims to examine nutritional interventions that could be adopted in order to overcome such complications. The present review summarises some of the more recent findings from a range of nutritional interventions in both small and large animals that are beginning to uncover novel pathways by which long-term health can be determined. These interventions include nutritional manipulations that can increase or decrease blood pressure in the resulting offspring as well as indicating their dissociation from adaptations in the kidney. Particular emphasis will be placed on growth during lactation in conjunction with the extent to which central and peripheral tissue adaptations can act to amplify, or protect, the offspring from later disease when born to nutritionallymanipulated mothers.
\end{abstract}

Blood pressure: Growth: Lactation: Metabolism

To date, the most-widely-studied stage of development in relation to the early origins of later adult disease has been during pregnancy (McMillen \& Robinson, 2005; Symonds et al. 2007). The reason is that birth weight (with or without placental weight) has been the main end point from the majority of historical and prospective human studies of later adverse health-outcome measures (Barker, 1994; Godfrey \& Robinson, 1997; Barker, 1998). It is becoming clear, from more extensive investigations in which postnatal and/or early childhood growth measurements are available, that changes in growth over this period may be as, or even more, important in predicting future health problems (Barker et al. 2005; Singhal, 2005). Indeed, prevention of accelerated growth over the first 6 months of life could potentially reduce the incidence of later metabolic disturbances (Ekelund et al. 2007). The aim of the EU Early Nutrition Project is, thus, to integrate results from clinical, epidemiological and animal studies in order to optimise nutrition during early development (Demmelmair et al. 2006).

The concept that postnatal growth rather than prenatal growth is a more robust predictor of later adult disease is supported by findings from contemporary intervention studies (Singhal \& Lucas, 2004) that have shown strong relationships between postnatal growth and components of the metabolic syndrome. This notion is perhaps not unexpected, given the increasing number of reports showing the close relationship between infant 'catch-up' growth and later obesity (Rogers \& the EURO-BLCS Study Group, 2003). In addition, a combination of low birth weight and faster growth after birth impair vascular structure and function (Singhal \& Lucas, 2004). The extent to which these adverse outcomes can have the same origin remains a matter of debate. To date, a majority of animal studies have focused on blood pressure control, because it is potentially the greatest health concern in adult populations 


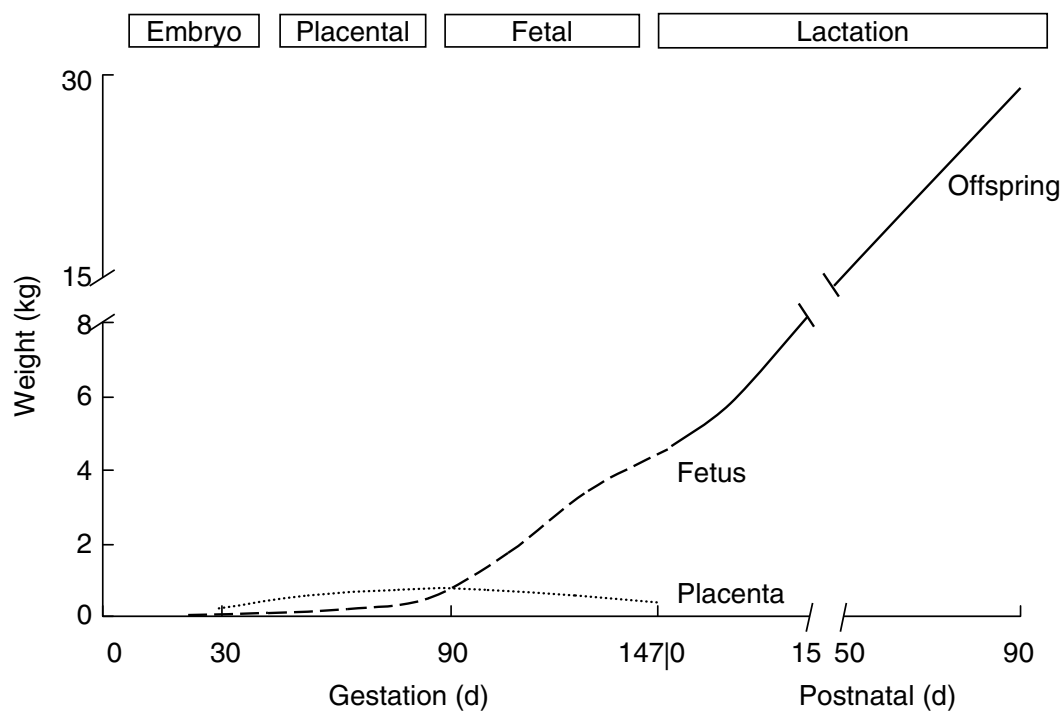

Fig. 1. Summary of the change in body weight, and hence growth rate, between conception and the end of lactation for the sheep.

(Armitage et al. 2004). In addition, in small-animal models long-term cardiovascular effects following changes in maternal dietary composition appear to be more readily programmed (McMillen \& Robinson, 2005), whereas effects on obesity are only seen with much-more-severe changes in the maternal diet (Vickers et al. 2001).

It is the aim of the present review, therefore, to consider the extent to which the findings from animal studies may add support to the concept of 'postnatal origins of adult disease'. Thus, it will be necessary to compare and contrast those investigations in which prenatal nutritional interventions specifically compromise weight at birth as opposed to how a switch in the maternal diet soon after birth may impact on maternal lactational performance and, thereby, represent the primary mediator of longer-term cardiovascular and metabolic maladaptation in the offspring. Currently, one study (Wyrwoll et al. 2006) has shown the potential for the fetal programming effects of maternal dexamethasone administration (for the development of the lungs of babies expected to be born prematurely) to be overcome when the offspring are cross-fostered onto dams fed a diet rich in $n-3$ fatty acids.

\section{The impact of the timing and duration of changes in the maternal diet during development on later blood pressure}

To date, a majority of animal studies have focused on the impact of manipulating the mother's diet either throughout pregnancy or at specific periods of pregnancy (Symonds et al. 2006, 2007), with little attention given to the lactational or post-weaning period, which represents the period of most-rapid early postnatal growth (Fig. 1). As will be summarised, this period could be very important when assessing the relative impact of any nutritional manipulations on cardiovascular control in the offspring. At the same time, it must be remembered that maturation of a number of key organ and endocrine pathways likely to mediate many of the cardiovascular and related adaptations in nutritionally-programmed offspring occur after birth rather than before birth in rodents, which is not the case in infants or large mammals (Symonds et al. 2007). These pathways include central pathways in the brain involved in appetite control (Bouret et al. 2004), as well as the establishment of nephron number in the kidney (Wintour \& Moritz, 1997).

A further critical component in the interpretation of rodent experiments is how blood pressure is actually assessed, because it is now apparent in studies using nutritionally-manipulated adult rats that very different interpretations can be drawn depending on the technique used (D'Angelo et al. 2005). Blood pressure as measured by the tail-cuff method tends to be higher than intra-arterial blood pressure, and this disparity is likely to be a result of the considerable stress imposed during the handling, warming and restraint involved (Tonkiss et al. 1998). This outcome is not surprising given that the technique was only originally fully validated in adult hypertensive rats (Bunag, 1973). In this context adult rats fed on a high-fructose diet (i.e. $660 \mathrm{~g}$ fructose and $120 \mathrm{~g}$ lard/ $\mathrm{kg}$ ) for 8 weeks show no change in resting blood pressure when measured by telemetry, whereas the blood pressure in response to stress, as induced by subjecting the animals to the tail-cuff procedure, is raised (D'Angelo et al. 2005). These animals are also insulin resistant and hyperglycaemic. The differential outcomes on blood pressure under resting conditions as opposed to external stress is a fundamental concept that must be taken into account when considering this type of results obtained from nutritionally-programmed animals. As a result, specific mention will be made throughout the present review when blood pressure is only measured by the tail-cuff procedure.

The most-widely-adopted maternal nutritional interventions that result in higher blood-pressure responses in the offspring are feeding a diet that has a $50 \%$ reduction in 
protein (in conjunction with a proportionate increase in carbohydrate content, i.e. low-protein high-carbohydrate; LP:HC) or reducing total food intake by $70 \%$ compared with ad libitum intake (Armitage et al. 2004; McMillen \& Robinson, 2005). It should be noted that these types of diets are not typical of those consumed by contemporary women living in either the developing or developed world, in which excess rather than insufficient macronutrient intake is becoming increasingly prevalent.

Another important consideration is the potential genderspecific divergence in the postnatal outcome. Males appear to be far more susceptible to some of the detrimental effects of nutritional programming compared with females (Khan et al. 2003). One contributing factor for this gender difference is presumably the much higher body weight attained by male rats compared with female rats and, thus, their faster juvenile growth rates (Symonds \& Gardner, 2006). Consequently, the metabolic and oxidative stress imposed on some (if not all) organs can be much greater in males than females, thereby reducing their lifespan considerably (Tarry-Adkins et al. 2006).

\section{Maternal dietary manipulation during development and programming of lower blood pressure in the offspring}

When considering the relative contributions of the prenatal and postnatal diets to later blood pressure control it is necessary to focus on more-recent studies that strongly indicate that there is not a simple relationship between maternal consumption of an LP:HC diet and raised blood pressure in the offspring (Fernandez-Twinn et al. 2006; Hoppe et al. 2007). Consequently, depending on how long this diet is fed to both the mother and the offspring, very different effects on blood pressure are seen, as summarised in Fig. 2.

When the mother continues to consume a LP:HC diet through lactation the offspring do not exhibit 'catch-up' growth and their blood pressure is the same as that of the controls, even when switched to the same standard diet at weaning (Fernandez-Twinn et al. 2006). In contrast, if the offspring are maintained on a LP:HC diet after weaning, then as adults they actually show a lower blood pressure than controls, an adaptation that is maintained even when they are fed a diet that is high in salt (Hoppe et al. 2007). Again, this adaptation is accompanied by the maintenance of a lower body weight through to adulthood.

The finding that maternal nutrient restriction programmes lower blood pressure in the offspring is not an isolated report and is confirmed by the findings of another study in which a $50 \%$ global reduction in maternal food intake was maintained through pregnancy (Brennan et al. 2006). After maternal diet was restored during lactation, the adult offspring were found to maintain a lower blood pressure throughout the $24 \mathrm{~h}$ period of assessment. This outcome was found despite the offspring of nutrientrestricted mothers being smaller from birth up to $2 \mathrm{~d}$ of age. A notable finding in this study was that nutrientrestricted mothers did not increase their body weight until the final $3 \mathrm{~d}$ of gestation. However, the weights of all their

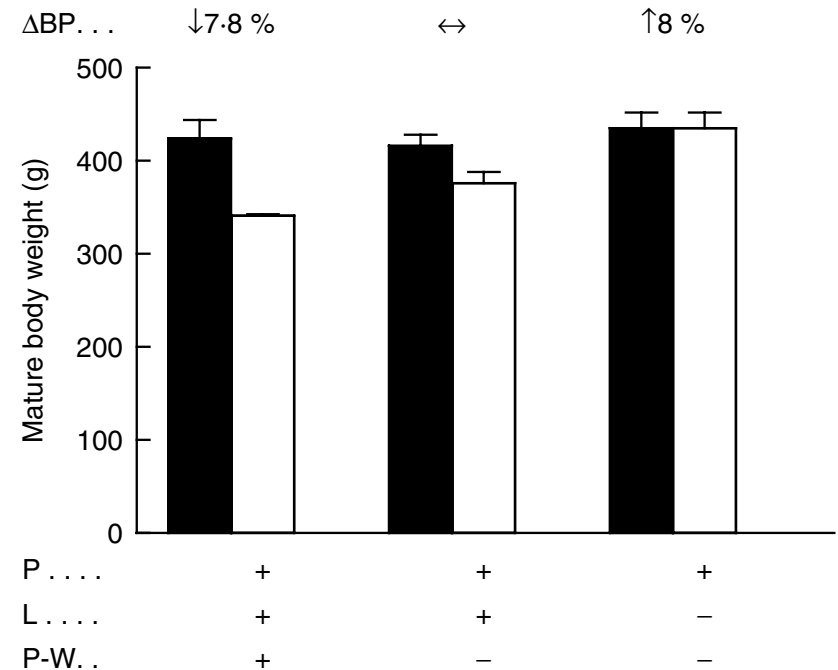

Fig. 2. Summary of the relationship between the duration of feeding a low-protein high-carbohydrate diet $(\square)$ and mature body weight in male rats and its relationship with the difference in blood pressure $(\triangle \mathrm{BP})$ between these offspring and those born to control dams ( $\boldsymbol{\square})$. $\downarrow$, Decrease; $\longleftrightarrow$, no change; $\uparrow$, increase; $P$, pregnancy; $L$, lactation; P-W, post-weaning. Values are means with their standard errors represented by vertical bars. There was no difference in mature body weights between any of the control groups. (Based on Woods et al. 2001; Fernandez-Twinn et al. 2006; Hoppe et al. 2007.)

major organs were maintained, which suggests that their lower body weight was a consequence of fat and muscle tissue mobilisation; adaptations that may be important in ensuring lactational performance is not greatly impaired and, thus, postnatal growth rate is unaffected. This finding may be important because in earlier studies the offspring of mothers that were more-severely globally nutrient restricted (i.e. fed only $30 \%$ ad libitum intake) did not restore their body weight to that of controls even when they were cross-fostered onto normally-fed dams (Vickers et al. 2000). Cross-fostering could, however, result in a substantially greater increase in milk supply to these offspring such that even though they maintain a lower body weight their blood pressure (as measured by the tail-cuff technique) is elevated (Vickers et al. 2000). It is, therefore, necessary to consider both actual growth rate achieved as well as what would be optimal for longer-term health. In this context, it is remarkable that the adverse outcomes in offspring born to dams fed only $30 \%$ ad libitum intake are prevented when leptin is administered from day 3 to day 13 after birth, resulting in a dramatic loss in weight of these pups (Vickers et al. 2005).

An explanation for the impact of specific maternal nutritional interventions on later blood pressure, even when these interventions are terminated at birth, therefore needs to take into account differences in growth rates between groups. In this context, the apparent gender-specific effect of blocking maternal glucocorticoid synthesis on the offspring's blood pressure (as measured by the tail-cuff procedure) at 4 weeks of age may be explained by the fact that it is accompanied by a pronounced reduction in postnatal growth rate (McMullen \& Langley-Evans, 2005). Given 
Table 1. Summary of the differences in kidney structure and function between male and female adult rats

\begin{tabular}{lccl}
\hline Kidney measurement & Male & Female & \multicolumn{1}{c}{ Reference } \\
\hline Weight $(\mathrm{g} / \mathrm{kg})$ & $0 \cdot 70$ & $0 \cdot 75$ & Woods \& Weeks (2005) \\
Nephron no. & $300000^{*}$ & $250000^{*}$ & Woods et al. (2001, 2005) \\
NO synthase activity (pmol/min per mg protein) & $7 \cdot 3$ & $4 \cdot 2$ & Attia et al. (2003) \\
Glomerular filtration rate $(\mathrm{ml} / \mathrm{min})$ & $3 \cdot 8$ & $2 \cdot 1$ & Woods (2006) \\
Effective renal plasma flow $(\mathrm{ml} / \mathrm{min})$ & $10 \cdot 5$ & $6 \cdot 4$ & Woods (2006) \\
Urinary protein excretion $(\mathrm{mg} / \mathrm{d})$ & 16 & 2 & Woods \& Weeks (2005) \\
\hline
\end{tabular}

${ }^{\star}$ Approximate nos.

the critical importance of glucocorticoids in ensuring normal mammary development and function (Quirk et al. 1986; Stelwagen et al. 1998), it is not unexpected that when maternal glucocorticoid synthesis is blocked her lactational capacity would be impaired.

Another recent study (Torrens et al. 2006) has shown that supplementation of the LP:HC diet with folic acid $(5 \mathrm{mg} / \mathrm{kg})$ can also reduce blood pressure in the resulting offspring when assessed by the tail-cuff procedure at 15 weeks of age. This reduction may be considered a surprising adaptation given that the LP:HC diet has adequate folic acid (i.e. $1 \mathrm{mg} / \mathrm{kg}$ ). Furthermore, rats exhibit coprophagia, so there is a substantial contribution of intestinal fermentation to folic acid synthesis. Consequently, the rats must be given succinyl sulfathiazole to inhibit this process in order to induce folate deficiency (Devlin et al. 2005). Folic acid supplementation in women, at least from 20 weeks of gestation, has no placental effects (Klingler et al. 2006). There is currently no information as to whether postnatal growth is affected in offspring born to dams that consume excess folic acid (Torrens et al. 2006) or whether folate could affect mammary development or function.

It is conceivable that lactational performance could be affected because folic acid supplementation can impair folate secretion into milk (Mackey \& Picciano, 1999). It also disrupts the normal inverse relationship between dietary folate and plasma homocysteine (Mackey \& Picciano, 1999), which may be related to changes in maternal folic acid metabolism (Smith et al. 1983). Lactation is accompanied by a dramatic reduction in folate concentration (Houghton et al. 2006), so such adaptations would be potentially exacerbated when dams are fed a diet in which folic acid supplementation is stopped after birth. It would therefore appear imperative that any effects of nutritional manipulation during pregnancy on growth and/or body composition through lactation must be studied subsequently.

Further indirect evidence that when postnatal growth is unaffected then, irrespective of the prenatal environment, blood pressure is similarly unaffected, is provided from large-animal studies (Gardner et al. 2004; Gopalakrishnan et al. 2005). These studies indicate that resting blood pressure is initially lower in nutrient-restricted offspring (Gopalakrishnan et al. 2005), and when they are raised under standard field conditions blood pressure is only modestly increased before feeding (Gopalakrishnan et al. 2004). Any potentially adverse outcomes may, however, be amplified when later growth is enhanced (Symonds et al. 2006).

\section{Nutritional programming of the kidney and its relationship with blood pressure control}

One organ that is particularly sensitive to nutritional programming is the kidney, in which the most consistent response is a reduction in nephron number (Zandi-Nejad et al. 2006). In rats there is an appreciable difference in kidney structure and function between males and females, which appears to be directly related to longevity (TarryAdkins et al. 2006). As summarised in Table 1, the kidneys of males possess more nephrons than those of females, and urinary protein excretion is substantially raised (approximately 6-fold) together with effective renal plasma flow and glomerular filtration rate (Woods, 2006). In addition, male rats have lower endothelial NO synthase activity (Attia et al. 2003). Ultimately, a combination of increased workload on the kidney, together with greater susceptibility to renal damage, could explain why male kidneys show increased cellular senescence, loss of function and, ultimately, male rats die earlier than females (TarryAdkins et al. 2006).

There is no evidence, however, that blood pressure is substantially different between male and female rats (Woods, 2006; Wyrwoll et al. 2006) and, indeed, there can be substantial functional deficits in the kidney of males that can actually be accompanied by a reduction in blood pressure (Hoppe et al. 2007). Male rats appear to be potentially more susceptible than females to the effects on later blood pressure after being born to mothers that consumed a LP:HC diet (Woods et al. 2001, 2005). This gender-specific outcome has been suggested to reside in the lack of any nutritional programming effect on the renin-angiotensinogen axis within the female kidney (Woods et al. 2005); gender has no influence on this axis in large mammals such as sheep (Whorwood et al. 2001). A comparison of postnatal growth rates between the two studies (Woods et al. 2001, 2005) conducted in the same laboratory indicates a striking difference (Fig. 3). Male offspring of mothers fed a LP:HC diet throughout pregnancy, but not the offspring of those fed a control diet, can be seen to have grown substantially faster during lactation. Furthermore, only those offspring that show a relative acceleration of postnatal growth go on to exhibit a higher blood pressure as adults (Fig. 3). There are a number 

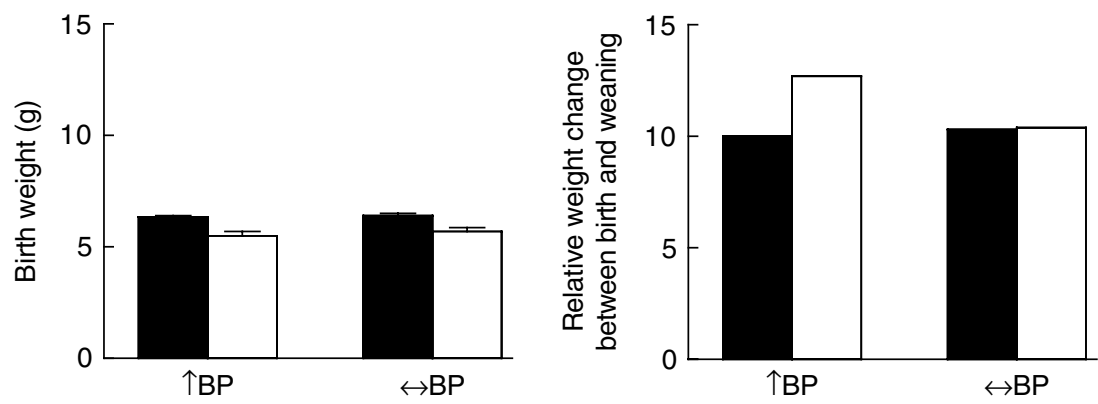

Fig. 3. Comparison of the difference in growth rates between birth and weaning and its relationship with changes in blood pressure in these offspring. ( $\square$ ), Low-protein highcarbohydrate diet; $(\boldsymbol{\square})$, controls; BP, blood pressure; $\uparrow$, increase; $\longleftrightarrow$, no change. Values are means with their standard errors represented by vertical bars. (From the work of Woods et al. 2001, 2005.)

of additional explanations as to why males selectively show this adaptive response, including the possibility that their higher growth rate is critical and may be related to the differential effects of lactation on postnatal development between males and females. It is therefore essential that similar lactational environments are maintained between studies in order to ensure valid comparisons are made.

\section{Other factors determining the relationship between kidney function and blood pressure control}

Given the increasing evidence that a deficit in nephron number does not directly impact on later blood pressure control in nutritionally-programmed offspring (Hoppe et al. 2007) and in the general population (Kett \& Bertram, 2004), it is necessary to consider other explanations for how kidney function can be differentially affected such that hypertension may result. Observations from adult animals and human subjects indicate that excess weight gain is a major risk factor for CVD that impacts on kidneymediated blood pressure regulation through impaired renal pressure natriuresis (Hall, 2003). This effect is primarily mediated through renal sympathetic activity, which is increased in obese individuals (Landsberg \& Krieger, 1989; Esler, 2000; Hall et al. 2001). Increased food intake and a concomitant rise in body fat mass, plasma leptin concentrations and glucose intolerance could lead to enhanced sympathetic stimulation of the kidney, thereby causing hypertension. However, can these maladaptations be programmed in utero (Symonds et al. 2005)?

In relation to the relative importance of the prenatal and the postnatal diet in excess fat deposition, a majority of small and large mammals are born with minimal fat reserves in which the major component is brown adipose tissue rather than white adipose tissue (Cannon et al. 1988; Bispham et al. 2005). Critically, brown adipose tissue is located in very different regions in small and large mammals; it is found in the intrascapular region in rodents but around the central organs such as the kidney in young sheep and infants. In the latter species brown adipose tissue is rapidly activated at birth, as both sheep and human subjects are precocial thermoregulators (Clarke et al. 1997b). For altricial thermoregulators, such as the rat, their brown fat is not fully activated until they start to leave their nest, which is coincident with maturation of their hypothalamic-pituitary axis (Obregon et al. 1996). Furthermore, in sheep, but not rats, perirenal adipose tissue is the most-rapidly-growing tissue after birth (Clarke et al. $1997 a$ ), although the extent to which this process can be preferentially promoted has yet to be shown.

Gender differences in fat deposition have been shown in rats. Females possess appreciably more intrascapular brown fat than males from 1 month of age (Pearce et al. 2003), although this disparity does not appear to be accompanied by any difference in their white fat stores or plasma leptin concentrations (Wyrwoll et al. 2006). In this context it is possible that rats may never deposit sufficient adipose tissue around their kidneys for it to have a deleterious effect on their function, except in extreme situations in which the rat has a genetic predisposition to become obese (Kasiske et al. 1988). Thus, it is necessary to give due consideration to these comparative aspects of animal development in order to interpret data from studies in terms of current models of nutritional programming of later disease.

In providing insights into the current epidemic of obesity, which is also occurring at a much earlier age (Budge et al. 2005), it must be noted that a range of other explanations are available outside those currently given most attention, i.e. increased consumption of processed food and/or reduced physical activity. These aspects have recently been reviewed (Keith et al. 2006), and they include a number of developmental explanations, e.g. maternal age and a combination of intrauterine and intergenerational effects. To these explanations can readily be added the recognition that formula-fed infants show an accelerated growth trajectory compared with those who are breast-fed (Ong et al. 2002), and that this outcome becomes predictive of both later weight gain and obesity (Ong et al. 2006). Nutritional advice that is offered to parents in the future will need to reflect the importance of avoiding excess growth (Ekelund et al. 2006). Whilst optimal growth rate may differ between individuals, avoiding excess growth is also an important consideration 
in the nutritional support offered to previously-sick and/or premature infants in their recovery phase when it may have the potential to improve later cardiovascular health (Regan et al. 2006).

\section{The impact of diet on postnatal growth and later risk of metabolic disease}

With the increasing evidence that excess postnatal growth, particularly in those infants that are born premature or small at birth, can have deleterious longer-term consequences, it is perhaps surprising that the vital role that nutrition has after birth has not been more closely investigated within animal studies. It should be noted that milk produced by the rat has an approximately 10 -fold higher protein content and protein:sugar than in human milk (Prentice \& Prentice, 1995), which reflects the very different types of organ growth that occur after birth in these two species. An excessively-high carbohydrate intake in itself appears to be related to later insulin insensitivity in preterm infants (Regan et al. 2006), although whether this outcome is a direct effect of sugar or the accompanying lower protein intake is not known. It is suggested that this type of effect can be mediated by excess central fat deposition (Ibanez et al. 2006), which in offspring born to nutritionally-compromised mothers appears to be the primary factor that accompanies glucose intolerance in young adult sheep (Gardner et al. 2005). Indeed, the function of the pancreas appears to be largely unaffected in growthrestricted infants (Beringue et al. 2002).

Accelerated postnatal growth in small-for-gestationalage children is accompanied by a comparatively rapid rise in plasma insulin-like growth factor-I concentrations (Iniguez et al. 2006), which in young growing sheep closely follows the increase in perirenal adipose tissue (Clarke et al. 1997a). At the same time the accelerated adipose tissue growth in first-born offspring is accompanied by increased insulin-like growth factor sensitivity and hepatic secretory potential (Hyatt et al. 2007). Not only is adipose tissue the fastest growing organ in the postnatal period, but food intake is the primary factor determining its growth (Gate et al. 2000). Furthermore, the composition and endocrine sensitivity of adipose tissue soon after birth is very different compared with that in later life (Symonds et al. 2003; Dunger \& Ong, 2004; Gnanalingham et al. 2005; Lomax et al. 2007). This factor, together with the high carbohydrate composition of milk (Prentice \& Prentice, 1995), may contribute to its capacity to maintain such a high growth rate (compared with the fetus, Fig. 1) as well as having a greater impact on overall metabolic regulation (Budge \& Symonds, 2006).

It is not unexpected that there is a substantial drive towards increased adiposity, particularly in formula-fed infants who appear to consume more in the first 2 months of life than in later months (Ong et al. 2006). Breastfeeding is therefore protective against promoting early fat deposition (Harvey et al. 2007) and later obesity (Arenz et al. 2004). In the past, any extra weight, especially fat, gained during infancy may well have been lost in childhood, but in the current environment, in which weight gain rather than weight loss is the norm (Popkin et al. 2006a), the adverse long-term health (Kim \& Popkin, 2006) and socio-economic consequences are substantial (Popkin et al. 2006b).

In conclusion, an increased understanding of the components of milk that act to differentially affect adipose tissue growth and endocrine action has the potential to enhance the long-term health outcomes of not only the large proportion of the population that are fed infant formula, but particularly those that are born prematurely or small-for-dates. In this context, the type of projects funded by the EU in which there is a close working relationship between academic, clinical and industrial partners has a distinct opportunity to make substantial progress in this complex arena (Demmelmair et al. 2006). A combination of small- and large-animal models of the relative impact of both prenatal and postnatal nutritional interventions and their differential impact on long-term outcomes is thus predicted to make substantial progress in this area.

\section{Acknowledgements}

The author acknowledges support from the British Heart Foundation and the EU Sixth Framework Programme for Research and Technical Development of the European Community - The Early Nutrition Programming Project (FOOD-CT-2005-007036).

\section{References}

Arenz S, Ruckerl R, Koletzko B \& von Kries R (2004) Breastfeeding and childhood obesity - a systematic review. International Journal of Obesity 28, 1247-1256.

Armitage JA, Khan IY, Taylor PD, Nathanielsz PW \& Poston L (2004) Developmental programming of the metabolic syndrome by maternal nutritional imbalance: how strong is the evidence from experimental models in mammals? Journal of Physiology 561, 355-377.

Attia DM, Goldschmeding R, Attia MA, Boer P, Koomans HA \& Joles JA (2003) Male gender increases sensitivity to renal injury in response to cholesterol loading. American Journal of Physiology 284, F718-F726.

Barker D, Osmond C, Forsén T, Kajantie E \& Eriksson J (2005) Trajectories of growth among children who have coronary events as adults. New England Journal of Medicine 353, 18021809.

Barker DJP (1994) Mothers, Babies and Disease in Later Life. London: BMJ Publishing Group.

Barker DJP (1998) Mothers, Babies and Disease in Later Life, 2nd ed. Edinburgh: Churchill Livingstone.

Beringue F, Blondeau B, Castellotti MC, Breant B, Czernichow P \& Polak M (2002) Endocrine pancreas development in growthretarded human fetuses. Diabetes 51, 385-391.

Bispham J, Gardner DS, Gnanalingham MG, Stephenson T, Symonds ME \& Budge H (2005) Maternal nutritional programming of fetal adipose tissue development: differential effects on mRNA abundance for uncoupling proteins, peroxisome proliferator activated and prolactin receptors. Endocrinology 146, 3943-3949.

Bouret SG, Draper SJ \& Simerly RB (2004) Trophic action of leptin on hypothalamic neurons that regulate feeding. Science 304, 108-110. 
Brennan KA, Olson D \& Symonds ME (2006) Maternal nutrient restriction alters renal development and blood pressure regulation of the offspring. Proceedings of the Nutrition Society 65, 116-124.

Budge H, Gnanalingham MG, Gardner DS, Mostyn A, Stephenson T \& Symonds ME (2005) Maternal nutritional programming of fetal adipose tissue development: long term consequences for later obesity. Birth Defects Research Part C: Embryo Today: Reviews 75, 193-199.

Budge H \& Symonds ME (2006) Fetal and neonatal nutrition Lipid and carbohydrate requirements and adaptations to altered supply at birth. In The Textbook of Perinatal Medicine, pp. 1007-1016 [HN Winn and PD Gluckman, editors]. Great Yarmouth, Norfolk: Taylor \& Francis.

Bunag RD (1973) Validation in awake rats of a tail-cuff method for measuring systolic pressure. Journal of Applied Physiology 34, 279-282.

Cannon B, Connoley E, Obregon M-J \& Nedergaard J (1988) Perinatal activation of brown adipose tissue. In The Endocrine Control of the Fetus, pp. 306-320 [W Kunzel and A Jesen, editors]. Berlin: Springer Verlag.

Clarke L, Buss DS, Juniper DS, Lomax MA \& Symonds ME (1997a) Adipose tissue development during early postnatal life in ewe-reared lambs. Experimental Physiology 82, 10151017.

Clarke L, Heasman L, Firth K \& Symonds ME (1997b) Influence of route of delivery and ambient temperature on thermoregulation in newborn lambs. American Journal of Physiology 272, R1931-R1939.

D’Angelo G, Elmarakby AA, Pollock DM \& Stepp DW (2005) Fructose feeding increases insulin resistance but not blood pressure in Sprague-Dawley rats. Hypertension 46, 806-811.

Demmelmair H, von Rosen J \& Koletzko B (2006) Long-term consequences of early nutrition. Early Human Development 82, 567-574.

Devlin AM, Bottiglieri T, Domann FE \& Lentz SR (2005) Tissue-specific changes in H19 methylation and expression in mice with hyperhomocysteinemia. Journal of Biological Chemistry 280, 25506-25511.

Dunger D \& Ong K (2004) Abundance of adiponectin in the newborn. Clinical Endocrinology 61, 416-417.

Ekelund U, Ong K, Linne Y, Neovius M, Brage S, Dunger DB, Wareham NJ \& Rossner S (2006) Upward weight percentile crossing in infancy and early childhood independently predicts fat mass in young adults: the Stockholm Weight Development Study (SWEDES). American Journal of Clinical Nutrition 83, 324-330.

Ekelund U, Ong KK, Linne Y, Neovius M, Brage S, Dunger DB, Wareham NJ \& Rossner S (2007) Association of weight gain in infancy and early childhood with metabolic risk in young adults. Journal of Clinical Endocrinology and Metabolism 92, 98-103.

Esler M (2000) The sympathetic nervous system and hypertension. American Journal of Hypertension 13, 99S-105S.

Fernandez-Twinn DS, Ekizoglou S, Wayman A, Petry CJ \& Ozanne SE (2006) Maternal low-protein diet programs cardiac beta-adrenergic response and signaling in 3-mo-old male offspring. American Journal of Physiology 291, R429-R436.

Gardner DS, Pearce S, Dandrea J, Walker RM, Ramsey MM, Stephenson T \& Symonds ME (2004) Peri-implantation undernutrition programs blunted angiotensin II evoked baroreflex responses in young adult sheep. Hypertension 43, 1-7.

Gardner DS, Tingey K, van Bon BWM, Ozanne SE, Wilson V, Dandrea J, Keisler DH, Stephenson T \& Symonds ME (2005) Programming of glucose-insulin metabolism in adult sheep after maternal undernutrition. American Journal of Physiology 289, R947-R954.
Gate JJ, Clarke L, Bird JA, Lomax MA \& Symonds ME (2000) Effect of feeding level and thyroxine on adipose tissue development and growth in postnatal lambs. Experimental Physiology 85, 439-444.

Gnanalingham MG, Mostyn A, Gardner DS, Stephenson T \& Symonds ME (2005) Developmental regulation of adipose tissue: Nutritional manipulation of local glucocorticoid action and uncoupling protein 2. Adipocytes 1, 221-228.

Godfrey K \& Robinson S (1997) Maternal nutrition, placental growth and fetal programming. Proceedings of the Nutrition Society 57, 105-111.

Gopalakrishnan G, Gardner DS, Dandrea J, Langley-Evans SC, Pearce S, Kurlak LO et al. (2005) Influence of maternal prepregnancy body composition and diet during early-mid pregnancy on cardiovascular function and nephron number in juvenile sheep. British Journal of Nutrition 94, 938-947.

Gopalakrishnan G, Gardner DS, Rhind SM, Rae MT, Kyle CE, Brooks AN, Walker RM, Ramsay MM, Keisler DH, Stephenson T \& Symonds ME (2004) Programming of adult cardiovascular function after early maternal undernutrition in sheep. American Journal of Physiology 287, R12-R20.

Hall JE (2003) The kidney, hypertension, and obesity. Hypertension 41, 625-633.

Hall JE, Hilderbrandt DA \& Kuo J (2001) Obesity hypertension: role of leptin and sympathetic nervous system. American Journal of Hypertension 14, 103S-115S.

Harvey NC, Poole JR, Javaid MK, Dennison EM, Robinson S, Inskip HM, Godfrey KM, Cooper C, Sayer AA \& the SWS Study Group (2007) Parental determinants of neonatal body composition. Journal of Clinical Endocrinology and Metabolism 92, 523-526.

Hoppe CC, Evans RG, Moritz KM, Cullen-McEwen LA, Fitzgerald SM, Dowling J \& Bertram JF (2007) Combined prenatal and postnatal protein restriction influences adult kidney structure, function and arterial pressure. American Journal of Physiology 292, R462-R469.

Houghton LA, Sherwood KL, Pawlosky R, Ito S \& O'Connor DL (2006) [6S]-5-Methyltetrahydrofolate is at least as effective as folic acid in preventing a decline in blood folate concentrations during lactation. American Journal of Clinical Nutrition 83, $842-850$.

Hyatt M, Budge H, Walker D, Stephenson T \& Symonds ME (2007) Effects of maternal parity and late gestational nutrition on mRNA abundance for growth factors in the liver of postnatal sheep. American Journal of Physiology 292, R1934-1942.

Ibanez L, Ong K, Dunger DB \& de Zegher F (2006) Early development of adiposity and insulin resistance after catch-up weight gain in small-for-gestational-age children. Journal of Clinical Endocrinology and Metabolism 91, 2153-2158.

Iniguez G, Ong K, Bazaes R, Avila A, Salazar T, Dunger D \& Mericq V (2006) Longitudinal changes in insulin-like growth factor-I, insulin sensitivity, and secretion from birth to age three years in small-for-gestational-age children. Journal of Clinical Endocrinology and Metabolism 91, 4645-4649.

Kasiske BL, O’Donnell MP, Cleary MP \& Keane WF (1988) Treatment of hyperlipidemia reduces glomerular injury in obese Zucker rats. Kidney International 33, 667-672.

Keith SW, Redden DT, Katzmarzyk PT, Boggiano MM, Hanlon EC, Benca RM et al. (2006) Putative contributors to the secular increase in obesity: exploring the roads less traveled. International Journal of Obesity 30, 1585-1594.

Kett MM \& Bertram JF (2004) Nephron endowment and blood pressure: what do we really know? Current Hypertension Reports 6, 133-139.

Khan IY, Taylor PD, Dekou V, Seed PT, Lakasing L, Graham D, Dominiczak AF, Hanson MA \& Poston L (2003) 
Gender-linked hypertension in offspring of lard-fed pregnant rats. Hypertension 41, 168-175.

Kim S \& Popkin BM (2006) Commentary: understanding the epidemiology of overweight and obesity - a real global public health concern. International Journal of Epidemiology 35, 60-67.

Klingler M, Blaschitz A, Campoy C, Cano A, Molloy AM, Scott JM, Dohr G, Demmelmair H, Koletzko B \& Desoye G (2006) The effect of docosahexaenoic acid and folic acid supplementation on placental apoptosis and proliferation. British Journal of Nutrition 96, 182-190.

Landsberg L \& Krieger DR (1989) Obesity, metabolism and the sympathetic nervous system. American Journal of Hypertension 2, 125S-132S.

Lomax MA, Sadiq F, Karamanlidis G, Karamitri A, Trayhurn P \& Hazlerigg DG (2007) Ontogenic loss of brown adipose tissue sensitivity to $\beta$-adrenergic stimulation in the ovine. Endocrinology 148, 461-468.

McMillen IC \& Robinson JS (2005) Developmental origins of the metabolic syndrome: Prediction, plasticity, and programming. Physiological Reviews 85, 571-633.

McMullen S \& Langley-Evans SC (2005) Maternal low protein diet in rat pregnancy programmes blood pressure through sexspecific mechanisms. American Journal of Physiology 288, R85-R90.

Mackey AD \& Picciano MF (1999) Maternal folate status during extended lactation and the effect of supplemental folic acid. American Journal of Clinical Nutrition 69, 285-292.

Obregon M-J, Cannon B \& Nedergaard J (1996) Postnatal selective suppression of lipoportein lipase gene expression in brown adipose tissue (relative to the expression of the gene for the uncoupling protein) is not due to adrenergic insensitivity; a possible specific inhibitory effect of colostrum. Biochemical Journal 314, 261-267.

Ong KK, Emmett PM, Noble S, Ness A \& Dunger DB (2006) Dietary energy intake at the age of 4 months predicts postnatal weight gain and childhood body mass index. Pediatrics 117, e503-e508.

Ong KK, Preece MA, Emmett PM, Ahmed ML \& Dunger DB (2002) Size at birth and early childhood growth in relation to maternal smoking, parity and infant breast-feeding: longitudinal birth cohort study and analysis. Pediatric Research 52, 863-867.

Pearce S, Casteilla L, Gualillo O, Symonds ME \& Stephenson T (2003) Differential effects of age and gender on the postnatal responsiveness of brown adipose tissue to prolactin administration in rats. Experimental Physiology 88, 527-531.

Popkin BM, Conde W, Hou N \& Monteiro C (2006a) Is there a lag globally in overweight trends for children compared with adults? Obesity 14, 1846-1853.

Popkin BM, Kim S, Rusev ER, Du S \& Zizza C (2006b) Measuring the full economic costs of diet, physical activity and obesity-related chronic diseases. Obesity Reviews 7, 271293.

Prentice AM \& Prentice A (1995) Evolutionary and environmental influences on lactation. Proceedings of the Nutrition Society 54, 391-400.

Quirk SJ, Gannell JE, Fullerton MJ \& Funder JW (1986) Specificity and mechanism of biphasic action of glucocorticoids on alpha-lactalbumin production by rat mammary gland explants. Endocrinology 118, 909-914.

Regan FM, Cutfield WS, Jefferies C, Robinson E \& Hofman PL (2006) The impact of early nutrition in premature infants on later childhood insulin sensitivity and growth. Pediatrics 118, 1943-1949.

Rogers I \& the EURO-BLCS Study Group (2003) The influence of birthweight and intrauterine environment on adiposity and fat distribution in later life. International Journal of Obesity 27, 755-777.

Singhal A (2005) Endothelial dysfunction: role in obesity-related disorders and the early origins of CVD. Proceedings of the Nutrition Society 64, 15-22.

Singhal A \& Lucas A (2004) Early origins of cardiovascular disease: is there a unifying hypothesis? Lancet 363, 16421645.

Smith AM, Picciano MF \& Deering RH (1983) Folate supplementation during lactation: maternal folate status, human milk folate content, and their relationship to infant folate status. Journal of Pediatric Gastroenterology and Nutrition 2, 622628.

Stelwagen K, van Espen DC, Verkerk GA, McFadden HA \& Farr VC (1998) Elevated plasma cortisol reduces permeability of mammary tight junctions in the lactating bovine mammary epithelium. Journal of Endocrinology 159, 173-178.

Symonds ME, Budge H, Mostyn A, Stephenson T \& Gardner DS (2006) Nutritional programming of fetal development: endocrine mediators and long-term outcomes for cardiovascular health. Current Nutrition and Food Science 2, 389398.

Symonds ME, Budge H, Stephenson T \& Gardner DS (2005) Leptin, fetal nutrition and long term outcomes for adult hypertension. Endothelium 12, 73-79.

Symonds ME \& Gardner DS (2006) Experimental evidence for early nutritional programming of adult health in animals. Current Opinion in Clinical Nutrition and Metabolic Care 9, 278283.

Symonds ME, Mostyn A, Pearce S, Budge H \& Stephenson T (2003) Endocrine and nutritional regulation of fetal adipose tissue development. Journal of Endocrinology 179, 293-299.

Symonds ME, Stephenson T, Gardner DS \& Budge H (2007) Long term effects of nutritional programming of the embryo and fetus: mechanisms and critical windows. Reproduction, Fertility and Development 19, 53-63.

Tarry-Adkins JL, Ozanne SE, Norden A, Cherif H \& Hales CN (2006) Lower antioxidant capacity and elevated p53 and p21 may be a link between gender disparity in renal telomere shortening, albuminuria, and longevity. American Journal of Physiology 290, F509-F516.

Tonkiss J, Trzcinska M, Galler JR, Ruiz-Opazo N \& Herrera VLM (1998) Prenatal malnutrition-induced changes in blood pressure - Dissociation of stress and nonstress responses using radiotelemetry. Hypertension 32, 108-114.

Torrens C, Brawley L, Anthony FW, Dance CS, Dunn R, Jackson AA, Poston L \& Hanson MA (2006) Folate supplementation during pregnancy improves offspring cardiovascular dysfunction induced by protein restriction. Hypertension 47, 982-987.

Vickers MH, Breier BH, Cutfield WS, Hofman PL \& Gluckman PD (2000) Fetal origins of hyperphagia, obesity, and hypertension and postnatal amplification by hypercaloric nutrition. American Journal of Physiology 279, E83E87.

Vickers MH, Gluckman PD, Coveny AH, Hofman PL, Cutfield WS, Gertler A, Breier BH \& Harris M (2005) Neonatal leptin treatment reverses developmental programming. Endocrinology 146, 4211-4216.

Vickers MH, Reddy S, Ikenasio BA \& Breier BH (2001) Dysregulation of the adipoinsular axis - a mechanism for the pathogenesis of hyperleptinemia and adipogenic diabetes induced by fetal programming. Journal of Endocrinology 170, 323-332.

Whorwood CB, Firth KM, Budge H \& Symonds ME (2001) Maternal undernutrition during early- to mid-gestation programmes tissue-specific alterations in the expression of the 
glucocorticoid receptor, 11 $\beta$-hydroxysteroid dehydrogenase isoforms and type 1 angiotensin II receptor in neonatal sheep. Endocrinology 142, 2854-2864.

Wintour EM \& Moritz KM (1997) Comparative aspects of fetal renal development. Equine Veterinary Journal 24, Suppl., 5158.

Woods LL (2006) Maternal glucocorticoids and prenatal programming of hypertension. American Journal of Physiology 291, R1069-R1075.

Woods LL, Ingelfinger JR, Nyengaard JR \& Rasch R (2001) Maternal protein restriction suppresses the newborn reninangiotensin system and programs adult hypertension in rats. Pediatric Research 49, 460-467.
Woods LL, Ingelfinger JR \& Rasch R (2005) Modest maternal protein restriction fails to program adult hypertension in female rats. American Journal of Physiology 289, R1131-R1136.

Woods LL \& Weeks DA (2005) Prenatal programming of adult blood pressure: role of maternal corticosteroids. American Journal of Physiology 289, R955-R962.

Wyrwoll CS, Mark PJ, Mori TA, Puddey IB \& Waddell BJ (2006) Prevention of programmed hyperleptinemia and hypertension by postnatal dietary omega-3 fatty acids. Endocrinology 147, 599-606.

Zandi-Nejad K, Luyckx VA \& Brenner BM (2006) Adult hypertension and kidney disease: the role of fetal programming. Hypertension 47, 502-508. 